\title{
Optimization of Software Architecture Selection for the System Under Design and Reengineering
}

\author{
Olexandr Kharchenko, Ihor Raichev \\ Computer Informational Technologies Department \\ National Aviation University \\ Kyiv, Ukraine \\ kharchenko.nau@gmail.com, raichevi.e@gmail.com
}

\author{
Ihor Bodnarchuk, Natalia Zagorodna \\ Cyber Security Department \\ Ternopil Ivan Puluj National Technical University \\ Ternopil, Ukraine \\ bodnarchuk.io@gmail.com, zagorodna.n@gmail.com
}

\begin{abstract}
The problem of optimization of software system architecture choice is considered taking into account changes of requirements in iterative technologies of design and reengineering. The solution is offered on the base of correction of alternatives' characteristics which were accounted on previous iteration or modification of existing software system during reengineering. This method prevents recalculations for evaluation and selection process. The method of pairwise substitution is applied for alternatives' characteristics correction. Its concept lies in compensation on supremacy of criterion change. Multicriteria optimization of substitution is carried out using nonlinear scalar convolution what improves validity of selected decision.
\end{abstract}

Keywords - quality criteria, multicriteria selection, software architecture evaluation, AHP, substitution

\section{INTRODUCTION}

Modern technologies of software systems design, such as extreme programming, SCRUM technics and some other are iterative. Changes into requirements or restrictions can be made during each iteration what cause the changes in corresponding parts of the project including the architecture. Changes of the domain requirements can be made also during software system (SWS) maintenance, what usually leads to changes in software. Thus, the software architecture (SA) should be changed initially because it influences critically onto software system quality. The selection of the architecture is made from the set of alternatives designed on the base of functional requirements from standard components (patterns). The assessments of all quality criteria are calculated for selection of the best variant of architecture. Then on the base of obtained assessments the multicriteria decision making problem of architecture choice is carried out.

The most efficient way of solution the problem of alternatives assessment using chosen quality criteria is Saaty's Analytic Hierarchic Process (AHP) [1], [2] or its modification (MAHP) [3].

The essential disadvantage of AHP application is limited quantity of alternatives, which can be evaluated simultaneously $(n \leq 7 \pm 2)$. It is caused by the inconsistency of the matrix of pairwise comparisons which increases with the number of alternatives [2].

A. Pavlov offered the modification of AHP in [3], where weight coefficients of alternatives are estimated based on condition of minimization of inconsistency of the matrix of pairwise comparisons, what leads the initial problem to the problem of mathematical programming. Application of modified AHP for the problem of the alternative architectures of SWS assessment for large quantity of alternatives is discussed in [4], [5]. Relative assessment of alternatives is estimated on the base of expert information in these methods. If requirements to SWS are changed during current iteration of design the expert assessment and calculation of alternatives evaluations must be repeated again. Since in case of iterative SWS design technologies the processes can run on some stages of software life cycle (SWLC) at the same time on the base of certain architecture decision, then the change of this decision requires amends in few parts of the project.

The procedure of correction on the base of substitution of quality criteria of base architecture and its following optimization is offered for decreasing of required changes in the project dealt with changes of the requirements to the SWS. It will allow to make minimum changes in all parts of the project and do not exceed the project budget.

The mathematical model of correction is developed using axiomatic theory of criteria importance [6] and results of the research conducted in [7]. The problem of optimization of global quality criterion for the architecture under restrictions defined by the model of correction is determined for selection of the proper values of criteria corrections. Let discuss two cases of the global criterion: linear and nonlinear scalar convolutions. Since application of linear scalar convolution has essential restrictions [8] we suggest to discuss the usage of nonlinear scalar convolution offered in [9]. The objective function which depends on the level of "the tension of the situation" estimated by the proximity of criteria values to their restrictions is optimized there. The iteration procedure of simplex planning is used for formalizing of the process of criteria weights estimation. Obtained optimal values of the criteria corrections are used for modification of the SWS architecture.

\section{THE MATHEMATICAL MODEL AND OPTIMIZATION OF THE ALTERNATIVES' QUALITY CRITERIA CORRECTIONS}

Given the set of the alternatives $\left\{A_{i}\right\}$ examined on previous iteration, and the relative assessments of the quality criteria 
values $\left\{K_{i s}\right\}$ calculated for them $(i=\overline{1, n} ; s=\overline{1, n})$, some alternative $\left\{A_{i}\right\}$ was chosen as main one. As the result of changes, it became not the best among other alternatives for some quality criteria. The problem of correction of its characteristics is formulated in order to make it the best. For this case the modification of chosen architecture decision should be made in such way that it will become the best for each criterion. We use the concept of criteria comparability [8] for development of the model of criteria correction.

The concept of comparability by substitution of criteria $K_{r}$ and $K_{s}$ means that for any alternative $A_{i}$ the compensation on superiority of some change of criterion $K_{r}$ is possible by some change of criterion $K_{s}$.

Ratio between value of possible changes of criteria $K_{r}$ and $K_{s}$ is defined by the essence of these criteria and achieved tradeoff regarding to their importance.

That is, if $A_{i}^{p}$ is an alternative that substitutes the alternative $A_{i}$ by correction of $K_{r}$ and compensation of $K_{s}$ then their corrected values will be equal to:

$$
\bar{K}_{r}^{i p}=\bar{K}_{r}^{i}-\delta_{r}, \bar{K}_{s}^{i p}=\bar{K}_{s}^{i}+\delta_{s i}, \delta_{s i}=f\left(r, s, \bar{K}, \delta_{r}\right),
$$

where $\bar{K}$ is a vector of criteria values.

Let write down relation for compensation at a substitution for the set of components of the vector $\bar{K}^{i}$ of alternative $A_{i}$ which we want to make better than $A_{j}$ :

$$
\delta \bar{K}_{r}^{i r_{z}}=C_{r}^{i r_{z}} \cdot \delta K_{r}^{i}, r_{z} \in R_{i}^{2}(r), r \in R_{i}^{1}
$$

where $\delta \bar{K}_{r}^{i r_{z}}$ is possible decreasing value of the component $\bar{K}_{r}^{i}$ for increasing the component $\bar{K}_{r_{z}}^{i}$;

$R_{i}^{1}$ is a set of indices $r$ for which $\bar{K}_{r}^{i z}>\bar{K}_{r}^{j}, j=\overline{1, n} ; i \neq j$;

$R_{i}^{2}(r)$ is a given for the set of indices $R_{i}^{1}$ such that the components $\bar{K}_{r}^{i}, r \in R_{i}^{1}$ may take part in substitution of the components $\bar{K}_{s}^{i}, s \in R_{i}^{2}(r)$;

$$
C_{r}^{i r_{z}} \text { are chosen coefficients of proportionality. }
$$

The components of the vector $\bar{K}^{i}$ after substitution are estimated as follows:

$$
\begin{aligned}
& \bar{K}_{r}^{i p}=\bar{K}_{r}^{i}-\sum_{r_{z} \in R_{i}^{2}(r)} C_{r}^{i r_{z}} \cdot \delta \bar{K}_{r_{z}}^{i}, \quad r \in R_{i}^{1} ; \\
& \bar{K}_{r}^{i p}=\bar{K}_{r_{z}}^{i}+\sum_{r \in R_{i}^{1}} \sum_{r_{z} \in R_{i}^{2}(r)} \delta \bar{K}_{r_{z}}, \quad r_{z} \in S, s \bar{\in} R_{i}^{1}, r_{z} \in R_{i}^{2}(r) .
\end{aligned}
$$

The values of the correction of criteria $\delta \bar{K}_{r}^{i r_{z}}$ are estimated under condition of optimization of global architecture quality criterion. Let consider first the linear scalar convolution as such criterion:

$$
Y\left(A_{i}\right)=\sum_{j=1}^{n} \alpha_{j} \cdot K_{j}\left(A_{i}\right),
$$

where $\alpha_{j}$ are weight indices of criteria.

Mathematical models of the optimization problems depend on the decision-making strategy. For Pareto-optimal strategy the optimization model taking into consideration (3) will be as follows:

$$
\max Y\left(A_{i}\right)
$$

under restrictions:

$$
\begin{aligned}
& d_{r}, d_{s} \geq 0, r \in L_{j}^{1}, s \bar{\in} R_{j}^{1} \\
& \bar{K}_{r}^{j}-\sum_{r_{z} \in R_{j}^{2}(r)} \delta \bar{K}_{r}^{j r_{z}} \geq \max _{i}\left(\delta \bar{K}_{r}^{i}\right)+d_{r}, i \in \overline{1, n}, i \neq j, r \in R_{j}^{1} \\
& \bar{K}_{s}^{j}+\sum_{r \in R_{j}^{1} r_{z} \in R_{j}^{2}(r)} \frac{1}{d_{r}^{j r_{z}}} \delta \bar{K}_{r}^{j r_{z}} \geq \max \left(\bar{K}_{s}^{i}\right)+d_{s}, \\
& i=\overline{1, n}, i \neq j, r \bar{\in} R_{j}^{1}, r_{z}=s, \quad \exists r, s \in R_{j}^{2}(r) ; \\
& \sum_{r_{z} \in L_{j}^{2}(r)} \delta \bar{K}_{r}^{i r_{z}} \leq b_{K_{r}^{j}}, \quad j \neq i, r \in R_{j}^{1}, r_{z}=s .
\end{aligned}
$$

Here $\delta K_{r}^{j r_{z}}, s . d_{i}, i=\overline{1, n}$ are given coefficients estimated from the essence of each criterion, moreover $d_{i} \geq 0, i=\overline{1, n}$.

We can estimate the values of the corrections for the criteria $\delta \bar{K}_{r}^{i r_{z}}$ after solving the problem of linear programming (5), (6).

Linear scalar convolution of criteria (5) is chosen usually as global criterion. But as it was mentioned earlier obtained solution may be non-optimal when such criterion will be used.

Selection of criterial function must be made accounting of specificity of the problem, the principle that the decision maker (DM) is guided and accepted schema of trade-offs.

Let's select nonlinear criterial function following the principle "far from restrictions":

$$
y\left(A_{i}\right)=\sum_{j=1}^{m} \alpha_{j}\left(1-\bar{K}_{j}\left(A_{i}\right)\right)^{-1}, i=\overline{1, n} .
$$

Here $\bar{K}_{j}\left(A_{i}\right)=K_{j} / B_{j}, B_{j}$ is a restriction for $K_{j}$.

This function is nonlinear regarding to quality criteria. In case when some criteria values will approach to limit of restrictions the minimax model will be accepted for decision making:

$$
A_{\text {opt }}=\arg \min _{A_{i} \in A} \max _{j=1, m} K_{j}\left(A_{i}\right)
$$


For cases when criteria values are far from restrictions the model of integration optimality will be realized:

$$
A_{\text {opt }}=\arg \min _{A_{i} \in A} \sum_{j=1}^{m} \alpha_{j}\left(1-\bar{K}_{j}\left(A_{i}\right)\right)^{-1} .
$$

If there are both criteria for minimization and maximization so the integral quality criterion of the selected architecture will be represented as follows:

$$
\begin{aligned}
& Q\left(A_{i}\right)=\sum_{j \in L_{1}} \alpha_{j}\left(1-\bar{K}_{j}\left(A_{i}\right)\right)^{-1}+ \\
& +\sum_{j \in L_{2}} \alpha_{j}\left(\bar{K}_{j}\left(A_{i}\right)-1\right)^{-1}, \quad i=\overline{1, n},
\end{aligned}
$$

where $L_{1}$ is a set of criteria indices for minimization;

$L_{2}$ - is a set of criteria indices for maximization.

The values of $\alpha_{j}$ have to be estimated for making optimal decision of the problem of architecture selection based on the set of quality criteria according to Pareto. The method of simplex planning [8] is used for choosing and correction the weights values $\alpha_{j}$.

Now we can solve the problem of mathematical programming with nonlinear criterial function and linear restrictions (6) by substitution the criterion (7) into the expression (5).

\section{CASE STUDY FOR THE METHOD}

Let's apply the correction method in the problem described in [6] where selection of the architecture for distributed software system is done for managing of common work of few developer teams. Most important requirements were scalability, secure access for all project team members to the database and some other. Assessments of some alternatives represented by the project participants are shown in the Table I.

TABLE I. ASSESSMENTS OF ALTERNATIVES REGARDING TO THE QUALITY CRITERIA

\begin{tabular}{|c|l|c|c|c|c|}
\hline \multicolumn{2}{|c|}{$\begin{array}{c}\text { Quality attributes } \\
\text { (criteria) }\end{array}$} & \multicolumn{4}{c|}{ Alternatives } \\
\cline { 2 - 6 } & $\begin{array}{c}\text { THTJ } \\
\left(A_{1}\right)\end{array}$ & $\begin{array}{c}\text { THTD } \\
\left(A_{2}\right)\end{array}$ & $\begin{array}{c}\text { TWOT } \\
\left(A_{3}\right)\end{array}$ & $\begin{array}{c}\text { COAB } \\
\left(A_{4}\right)\end{array}$ \\
\hline $\mathbf{1}$ & Modifiability $\left(K_{1}\right)$ & 0,521 & 0,172 & 0,106 & 0,210 \\
\hline $\mathbf{2}$ & Scalability $\left(K_{2}\right)$ & 0,453 & 0,350 & 0,064 & 0,133 \\
\hline $\mathbf{3}$ & Performance $\left(K_{3}\right)$ & 0,201 & 0,204 & 0,347 & 0,246 \\
\hline $\mathbf{4}$ & Cost $\left(K_{4}\right)$ & 0,166 & 0,180 & 0,427 & 0,227 \\
\hline $\mathbf{5}$ & Development effort $\left(K_{5}\right)$ & 0,500 & 0,050 & 0,050 & 0,400 \\
\hline $\mathbf{6}$ & Portability $\left(K_{6}\right)$ & 0,268 & 0,268 & 0,256 & 0,218 \\
\hline
\end{tabular}

Here following alternatives are investigated: THTJ - threetired architecture on the base of J2EE platform, THTD - three tired architecture on the base of .NET platform, TWOT - two tired architecture with "fat" client, $\mathrm{COAB}$ - the architecture with distributed agent support.
Based on data analysis from Table I we select the most acceptable for correction and selection alternative THTJ. As we can see from the Table I this alternative THTJ surpasses all other on criteria $K_{1}, K_{2}, K_{5}$ and it is not the best on criteria $K_{3}$ and $K_{4}$. We need to correct assessments of the alternative $A_{1}$ such that for each criterion it will become not worse than three other architectures and it would be better on some criteria.

Here the set $R_{i}^{1} \rightarrow\left(\forall l \in L_{i}^{l}, \bar{K}_{l}^{i}>\bar{K}_{l}^{j}, i \neq j\right) \in\{1 ; 2 ; 5\}$ and correspondently $R_{i}^{2}=\{3 ; 4\}$. The criterion $K_{6}$ does not take part in the substitution. The problem is to use decreasing assessments on $1^{\text {st }}, 2^{\text {nd }}$ and $5^{\text {th }}$ criteria to increase assessments on $3^{\text {rd }}$ and $4^{\text {th }}$ but they must stay not worse that for three other alternatives. Since maximum assessment on $1^{\text {st }}$ criterion of second, third and fourth alternatives is 0,210 , on $2^{\text {nd }}$ criterion 0,350 , and on $5^{\text {th }}$ criterion is 0,40 so these restrictions look as follows:

$$
\begin{aligned}
& 0,521-\left(\delta \bar{K}_{13}+\delta \bar{K}_{14}\right) \geq 0,210+y \\
& 0,450-\left(\delta K_{23}+\delta K_{24}\right) \geq 0,350+0,8 \cdot y \\
& 0,5-\left(\delta \bar{K}_{53}+\delta \bar{K}_{54}\right) \geq 0,4+0,8 \cdot y .
\end{aligned}
$$

The restrictions where the assessments of third and fourth criteria that are under correction would be not worse than for three other alternatives look like following:

$$
\begin{aligned}
& 0,201+\left(1,6 \cdot \delta \bar{K}_{13}+1,25 \delta \bar{K}_{23}+1,3 \cdot \delta \bar{K}_{53}\right) \geq 0,347+0,5 \cdot y \\
& 0,166+\left(2,5 \cdot \delta \bar{K}_{14}+1,1 \cdot \delta \bar{K}_{24}+2 \cdot \delta \bar{K}_{54}\right) \geq 0,427+0,6 \cdot y .
\end{aligned}
$$

The coefficients of substitution $C_{l}^{i l m}$ are introduced by experts on the base of criteria importance.

The restrictions on maximum change of first, second and fifth criteria are following:

$$
\begin{aligned}
& \delta \bar{K}_{13}+\delta \bar{K}_{14} \leq 0,3 ; \\
& \delta K_{23}+\delta K_{24} \leq 0,1 \\
& \delta \bar{K}_{53}+\delta \bar{K}_{54} \leq 0,1 .
\end{aligned}
$$

As the result of the solution of the problem of optimization with stated restrictions we will obtain:

$$
\begin{aligned}
\delta \bar{K}_{13} & =0,12 ; \delta \bar{K}_{14}=0,18 ; \\
\delta \bar{K}_{23} & \equiv 0,04 ; \delta \bar{K}_{24}=0,06 \\
\delta \bar{K}_{53} & =0,07 ; \delta \bar{K}_{54}=0,03 ; y=0,13 .
\end{aligned}
$$

Corrected assessments of the architectures are represented in the Table II.

The alternative $A_{1}$ is now the best for all criteria except $K_{6}$ for which it is not worse than assessments of other alternatives. 
TABLE II. CORRECTED ASSESSMENTS OF ALTERNATIVES REGARDING THE QUALITY CRITERIA

\begin{tabular}{|c|l|c|c|c|c|}
\hline \multirow{2}{*}{$\begin{array}{c}\text { Quality attributes } \\
\text { (criteria) }\end{array}$} & $\begin{array}{c}\text { Alternatives } \\
\left(A_{1}\right)\end{array}$ & $\begin{array}{c}\text { THTD } \\
\left(A_{2}\right)\end{array}$ & $\begin{array}{c}\text { TWOT } \\
\left(A_{3}\right)\end{array}$ & $\begin{array}{c}\text { COAB } \\
\left(A_{4}\right)\end{array}$ \\
\hline $\mathbf{1}$ & Modifiability $\left(K_{1}\right)$ & 0,221 & 0,172 & 0,106 & 0,210 \\
\hline $\mathbf{2}$ & Scalability $\left(K_{2}\right)$ & 0,353 & 0,350 & 0,064 & 0,133 \\
\hline $\mathbf{3}$ & Performance $\left(K_{3}\right)$ & 0,431 & 0,204 & 0,347 & 0,246 \\
\hline $\mathbf{4}$ & Cost $\left(K_{4}\right)$ & 0,436 & 0,180 & 0,427 & 0,227 \\
\hline $\mathbf{5}$ & Development effort $\left(K_{5}\right)$ & 0,400 & 0,048 & 0,052 & 0,400 \\
\hline $\mathbf{6}$ & Portability $\left(K_{6}\right)$ & 0,268 & 0,268 & 0,256 & 0,218 \\
\hline
\end{tabular}

\section{CONCLUSIONS}

Iterative technologies of design that used widely for development of software products aiming to decrease of development time assume parallel processes running on some stages of SWS lifecycle. Thus, change of requirements for the SWS during design process requires amends in the architecture and respectively into all components of the project. It is offered to correct values of the quality criteria of the architecture with accounting of change of requirements in order to minimize the impact of these changes on the project quality and required corrections of the project. The mathematical model is developed on the base of the method "substitution - compensation". The problems of corrections optimization stated for the global quality criterion of SA as linear and nonlinear scalar convolutions were reduced to the problems of linear and nonlinear mathematical programming correspondently.

The example of practical applying of developed method is represented that demonstrates its capabilities.

It is planned as further researches to develop CASE tool on the base of developed models for automation of the processes of architecture corrections during projects management.

\section{REFERENCES}

[1] M. Svahnberg, C. Wholin, and L. Lundberg. A Quality-Driven DecisionSupport Method for Identifying Software Architecture Candidates. // Int. Journal of Software Engineering and Knowledge Engineering, 2003. 13(5): pp. 547-573.

[2] Saaty T. Decision Making with the Analytic Network Process./ Saaty T. Vargas L.// - N.Y.: Springer, 2006. 278 p.
[3] Pavlov A.A. Mathematical models of optimization for estimation of weights of objects in the method of pairwise comparisons. Pavlov A.A., Lishchuk E.I., Kut V.I. // System investigations and information technologies. - Kyiv: IPSA, - 2007. No. 2, pp. 13 - 21 .

Павлов А.А. Математические модели оптимизации для нахождения весов объектов в методе парныхсравнений. Павлов А.А, Лищук Е.И., Кут В.И. // Системні дослідження та інформаційні технології. - К. IICA, - 2007. №2, c. $13-21$.

[4] Kharchenko A.H. The method of multicriteria optimization of software architecture on the base of trade-offs analysis / Kharchenko A.G., Bodnarchuk I.O., Halai I.O. // Software engineering. - Kyiv: NAU. 2012. - No 3 - 4 (11-12). - pp. 5 - 11 .

Харченко О.Г. Метод багатокритеріальної оптимізації програмної архітектури на основі аналізу компромісів / Харченко О.Г., Боднарчук I.O., Галай I.O. // Інженерія програмного забезпечення. К.: НАУ.-2012. - № 3-4 (11-12). - c. 5-11.

[5] Kharchenko A. The method for comparative evaluation of software architecture with accounting of trade-offs/ Alexander Kharchenko, IhorBodnarchuk, VasylYatcyshyn // American Journal of Information Systems. -V. 2, No. 1. - 2014. - P. 20-25. Available online at http://pubs.sciepub.com/ajis/2/1/5

[6] Podinovskii V.V. Introduction into the theory of criteria importance in multicriteria decision making problems / Podinovsskii V.V. - M.: Phizmatlit, 2007. - 64 p.

Подиновский В. В. Введение в теорию важности критериев в многокритериальных задачах принятия решений / Подиновский В В. - М.: Физматлит, 2007. - 64 с.

[7] Павлов А.А. Оперативные алгоритмы принятия решений в иерархической системе Саати, основанные на замещении критериев / Павлов О.А., Ліщук К.І. // Вісник НТУУ “КПІ”. Інформатика, управління та обчислювальна техніка. К.: “ВЕК+”,2008.- №48. - С. $78-81$.

Pavlov A.A. Operative algorythms of decisions making in Saaty's hierarchy system based on the criteria substitution / Pavlov A.A., Lishchuk K.I. // Bulletin on NTUU “KPI”. Informatics, management and computers. K.: "VEK+", 2008. - No 48. - pp. 78 - 81 .

[8] A.N. Voronin , Yu. K. Ziatdinov Theory and practice of multicirteria decisions: Models, methods, realization. - Lambert Academic Publishing, 2013, 305 p.

А.Н. Воронин, Ю.К. Зиатдинов. Теория и практика многокритериальных решений: Модели, методы, реализация. Lambert Academic Publishing, 2013, 305 p.

[9] Ногин В.Д. Границы применимости распространенных методов скаляризации при решении задач многокритериального выбора // Методы возмущений в гомологической алгебре и динамика систем: Межвуз. сб. науч. тр. Саранск: Изд-во Мордов. ун-та, 2004, с. 59 68. URL - http://www.apmath.spbu.ru/ru/staff/nogin/nogin_p12.pdf

Nogin V.D. Limits of applicability of the widely used methods of scalarization in solving multicriteria choice problems // Perturbation methods in homological algebra and dynamics of systems:Interinstitute bulleting Saransk: Publ. of Mordovsk. Univer. 2004, pp. 59 - 68 . Accessible on: http://www.apmath.spbu.ru/ru/staff/nogin/nogin_p12.pdf 